\title{
The left anterior descending coronary artery ruptures - examples from the practice
}

\author{
Mario Sičaja*, Boris Starčević \\ University Hospital Dubrava, Zagreb, Croatia
}

Coronary artery perforation (CAP) remains a feared complication of percutaneous coronary intervention $(\mathrm{PCl})$. Here we present three cases of coronary artery rupture - all LAD perforations', which were treated accordingly. CAPs are classified according to the Ellis classification into three groups. Type 1 and 2 perforations are predominately caused by hydrophilic and stiff wires and do not require pericardial drainage or surgical intervention. Type 3 perforations are more often associated with stent and device use and can be initially managed by percutaneous methods, but might require surgical assistance. CAP complicating percutaneous coronary intervention is rare, and its morbidity and mortality vary directly with Ellis classification. Management discrepancies highlight the need to establish a uniform treatment paradigm for CAP.

KEYWORDS: coronary artery rupture, Ellis classification, percutaneous coronary intervention.

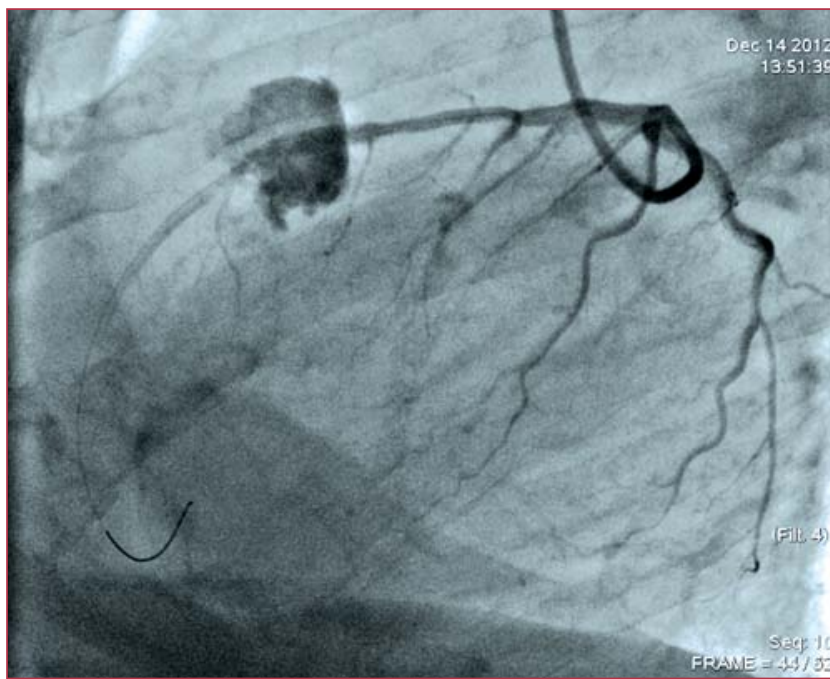

Figure 1. Example of the left anterior descending coronary artery rupture.

\section{Received: $10^{\text {th }}$ Mar 2013}

*Address for correspondence: Klinička bolnica Dubrava, Avenija Gojka Šuška 6, HR-10000 Zagreb, Croatia.

Phone: $+385-1-2902-444$

E-mail: mario.sicaja@zg.t-com.hr

\section{Literature}

1. Shimony A, Joseph L, Mottillo S, Eisenberg MJ. Coronary artery perforation during percutaneous coronary intervention: a systematic review and meta-analysis. Can J Cardiol. $2011 ; 27(6): 843-50$.

2. Fogarassy G, Apró D, Veress G. Successful sealing of a coronary artery perforation with a mesh-covered stent. J Invasive Cardiol. 2012;24(4):E80-3. 